\title{
Case Report: Dual Antiplatelet in Capsular Warning Syndrome
}

\author{
Azliza Ibrahim 1* , Ahmad Firdaus ${ }^{1}$, Alvin Oliver Payus², Abdul Hanif Khan ${ }^{3}$, Liyana Najwa ${ }^{3}$, \\ Hamidon Basri ${ }^{3}$, Mohd Fandi ${ }^{4}$
}

\author{
${ }^{1}$ Department of Neurology, Hospital Pengajar Universiti Putra Malaysia, Kuala Lumpur, Malaysia \\ ${ }^{2}$ Department of Medicine Based, Faculty of Health Sciences, Malaysia Sabah University, Sabah, Malaysia \\ ${ }^{3}$ Department of Neurology, Faculty of Medicine and Health Sciences, Universiti Putra Malaysia, Kuala Lumpur, Malaysia \\ ${ }^{4}$ Department of Radiology, Hospital Pengajar Universiti Putra Malaysia, Kuala Lumpur, Malaysia \\ Email: ^maizarah_84@yahoo.com, *azliza.i@upm.edu.my
}

How to cite this paper: Ibrahim, A., Firdaus, A., Payus, A.O., Khan, A.H., Najwa, L., Basri, H. and Fandi, M. (2021) Case Report: Dual Antiplatelet in Capsular Warning Syndrome. Neuroscience \& Medicine, 12, 55-61. https://doi.org/10.4236/nm.2021.122005

Received: February 20, 2021

Accepted: June 8, 2021

Published: June 11, 2021

Copyright (c) 2021 by author(s) and Scientific Research Publishing Inc. This work is licensed under the Creative Commons Attribution International License (CC BY 4.0).

http://creativecommons.org/licenses/by/4.0/

\section{(c) (i) Open Access}

\begin{abstract}
Background: Capsular warning syndrome (CWS) is defined as a recurrent stereotype transient lacunar syndrome without cortical symptoms. However, to date, there is limited literature proposed on the definitive treatment options for the prevention of persistent stroke in cases of capsular warning syndrome. Aim: The aim of this case report is to address dual antiplatelet therapy as a treatment choice in CWS to prevent progressive stroke. Case presentation: A 56-year-old man with several comorbidities experienced recurrent periods of limb weakness and dysarthria lasting 5 - 20 minutes with a complete resolution of symptoms in between. The fluctuating episodes lasted for 72 hours followed by a persistent minor stroke. A gadolinium-enhanced MRI scan of the brain revealed a right basal ganglia infarct. He was treated with dual antiplatelet, and his functional outcome was favourable at 90 days post stroke. Conclusion: Dual antiplatelet may be a beneficial therapeutic option in CWS in improving functional outcomes in the early neurological deficit and decreasing the clinical fluctuation.
\end{abstract}

\section{Keywords}

Capsular Warning Syndrome, Ischaemic Stroke, Aspirin

\section{Introduction}

Capsular warning syndrome (CWS) is a repetitive episode of motor and/or sensory symptoms. This condition is associated with a high risk of developing a complete stroke. Previous findings have shown that the incidence of CWS in TIA patients was $1.5 \%$ - 4.5\% [1] [2] [3]. The duration of each episode of CWS 
varied and one study found that the mean duration of each episode was $6.1 \mathrm{mi}-$ nutes [3]. Nicola et al. previously reported that CWS had a poor 7-day stroke risk forecast of 60 per cent [2] with the most frequent location was internal capsule (50\%). However, some studies have shown that ischaemic can occur in other locations including thalamus, midbrain, pons, and striatum [4] [5]. There is no definitive treatment for CWS. To our knowledge, various treatments were available for CWS, such as intravenous thrombolysis, single or double antiplatelet (DAPT), anticoagulant and vasopressor however there was no conclusive data [3] [6]-[12].

\section{Case Report}

A 56-year-old gentleman, with history of hypertension, dyslipidaemia, diabetes mellitus type 2 and morbid obesity presented with left sided weakness and numbness associated with dysarthria after waking up from sleep. He was well the night before. On examination, his vital signs were as follows; high blood pressure of $183 / 76$, pulse rate of 80 beats per minute with normal body temperature and oxygenation. On neurological examination, the Glasgow Coma Scale (GCS) was full 15/15 with the National Institutes of Health Stroke Scale (NIHSS) score of $4 / 42$. He was orientated but dysarthria speech. He had reduced muscle power of 3/5 over the left upper and lower limb with bilateral symmetrical reflexes and downward going plantar. No facial asymmetry, cranial nerve abnormalities, neglect, gaze paralysis or cerebellar ataxia were elicited. The sensory examination was normal. Other systemic examinations were unremarkable. Routine blood investigations were performed with the following results: haemoglobin (Hb) $15.9 \mathrm{~g} / \mathrm{dL}$, white blood count (WBC) $12.9 \times 10^{9} / \mathrm{L}$ and a platelet count of $394 \times 10^{9} / \mathrm{L}$. Lipid profile results were as follows; triglyceride (TG) $2.7 \mathrm{mmol} / \mathrm{l}$, low density lipoprotein (LDL) $2.5 \mathrm{mmol} / \mathrm{l}$ and high-density lipoprotein (HDL) $1.0 \mathrm{mmol} / \mathrm{l}$ (Table 1). His brain's magnetic resonance imaging (MRI) and magnetic resonance angiography (MRA) showed acute right basal ganglia infarction and small vessel disease respectively (Figures 1-3). He was not treated with thrombolytic therapy in view of his low NIHSS score and appeared out of the thrombolysis window. He was given with a combination of antiplatelet of aspirin and clopidogrel. In addition to the double antiplatelet (DAPT), he was also started with statin and antihypertensive. During his hospitalisation, he experienced 3 episodes of left hemiparesis with dysarthric speech lasting between 5 to 15 minutes with full resolutions of symptoms in between. These fluctuating neurological episodes typically begin upon waking up from sleep or at rest. Repeated MRI brain showed no new infarct lesion with non-evolving basal ganglia infarct. On the fourth day of his hospitalisation, he developed a permanent left hemiparesis and mild dysarthric speech. He then underwent an intensive rehabilitation, physiotherapy, occupational and speech therapy to restore his physical function. Upon discharge, his functional Modified Rankin Score (MRS) was three at discharge and improved to two at 90 days stroke assessment. He had a favourable physical function and to meet his own needs without assistance. 


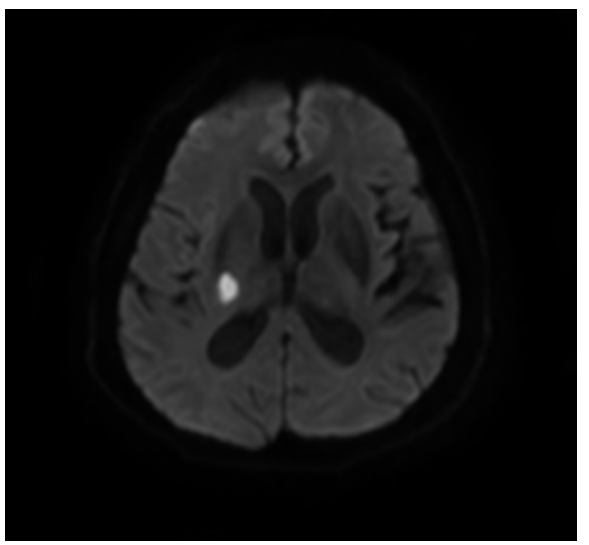

(a)

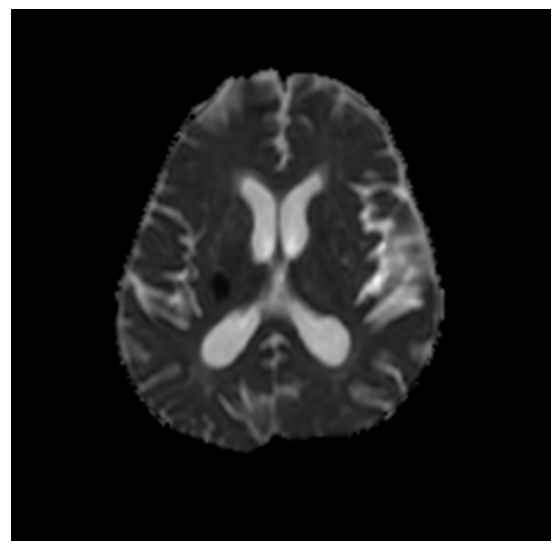

(b)

Figure 1. MRI Diffusion-weighted imaging/Apparent diffusion coefficient (DWI/ADC) showed presence of restricted diffusion seen at posterior limb of right internal capsule as evidenced by hyperintensity on DWI (a) and hypointensity on ADC (b).

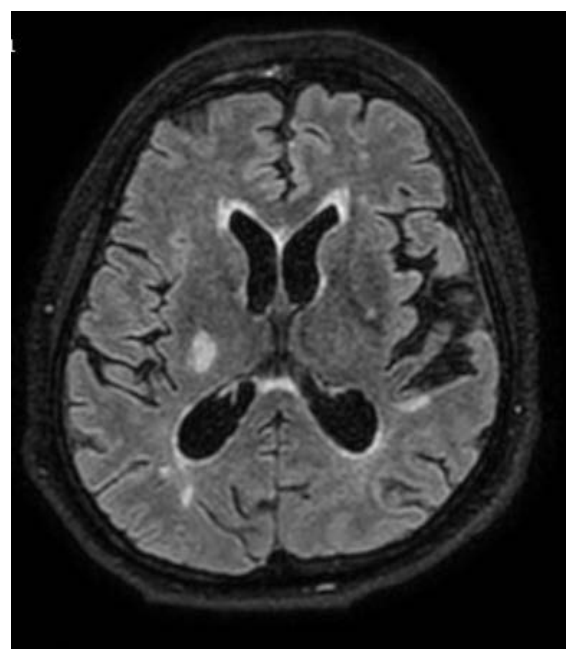

Figure 2. MRI FLAIR showed hyperintensity signal at posterior limb of right internal capsule and bilateral periventricular hyperintensities in keeping with small vessel disease.

Table 1. Blood investigations to assess the stroke risk.

\begin{tabular}{ccc}
\hline Blood Investigation & Result & Normal Range \\
\hline Total Cholesterol & $4.5 \mathrm{mmol} / \mathrm{l}$ & $<5.7 \mathrm{mmol} / \mathrm{l}$ \\
Triglyceride & $2.7 \mathrm{mmol} / \mathrm{l}$ & $<1.7 \mathrm{mmol} / \mathrm{l}$ \\
LDL-CHOL & $2.5 \mathrm{mmol} / \mathrm{l}$ & $<3.9 \mathrm{mmol} / \mathrm{l}$ \\
HDL-CHOL & $1.0 \mathrm{mmol} / \mathrm{l}$ & $<1.4 \mathrm{mmol} / \mathrm{l}$ \\
Haemoglobin & $15.9 \mathrm{~g} / \mathrm{d}$ & $12-18 \mathrm{~g} / \mathrm{dL}$ \\
White cell count & $12.9 \times 10^{9} / \mathrm{L}$ & $4.0-11.0 \times 10^{9} / \mathrm{L}$ \\
Platelet & $394 \times 10^{9} / \mathrm{L}$ & $150-400 \times 10^{9} / \mathrm{L}$ \\
Urea & $5.4 \mathrm{mmol} / \mathrm{L}$ & $1.7-8.0 \mathrm{mmol} / \mathrm{L}$ \\
Sodium & $135 \mathrm{mmol} / \mathrm{L}$ & $135-150 \mathrm{mmol} / \mathrm{L}$ \\
Potassium & $4.3 \mathrm{mmol} / \mathrm{L}$ & $3.5-5.0 \mathrm{mmol} / \mathrm{L}$ \\
Creatinine & $103 \mu \mathrm{mol} / \mathrm{L}$ & $60-120 \mathrm{umol} / \mathrm{L}$ \\
Calcium & $2.21 \mathrm{mmol} / \mathrm{L}$ & $2.10-2.55 \mathrm{mmol} / \mathrm{L}$
\end{tabular}




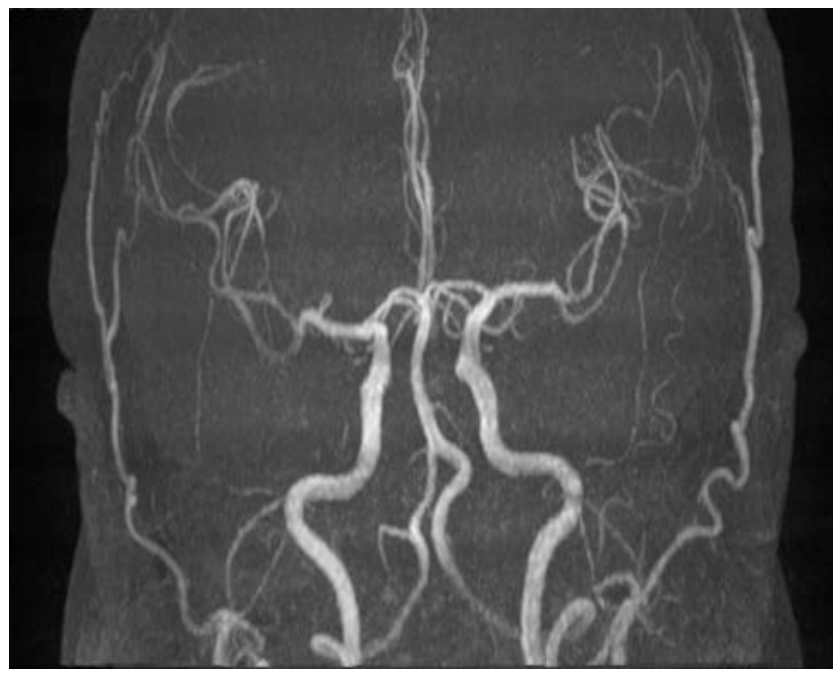

Figure 3. MRA showed both ICA, MCA, ACA, PCOM, ACOM and Vertebrobasilar are patent. ICA indicates Internal carotid artery; MCA, middle cerebral artery; ACA, Anterior cerebral artery; PCOM, Posterior communicating artery; and ACOM, Anterior communicating artery.

\section{Discussion}

Capsular warning syndrome consists of intermittent transient cerebral ischemia, which often occurs at the same time. Donnan et al. were the first person to identify a group of patients who had three or more identical episodes of "crescendo transient ischaemic attack" within 24 hours and affecting face, arm and leg without cortical symptoms [3]. In severe cases, CWS occurs as three or more recurrent episodes within 24 hours [13]. As in our case, the patient had three distinct episodes of neurological fluctuation within 48 to 72 hours. There is no exact pathophysiology for CWS but common risk factors such as hypertension, dyslipidaemia, diabetes, and smoking are correlated with CWS, which suggests that atherosclerosis may be associated with CWS pathogenesis. On the other hand, some authors have argued that intermittent haemodynamic changes secondary to structural arterial changes or hypertension may be the mechanism of action in CWS [3] [14]. Terai et al. has reported that serial MRI in initial transient symptoms of CWS denotes hypoperfusion of perforator arteries while ultimate core infarction reflects thrombosis in artery with diminished cerebral blood flow [15]. The clinical management of CWS has not been extensively studied. Different treatment modalities have been proposed, including intravenous thrombolysis [1] [16], single or double antiplatelet (DAPT) [8] [17], anticoagulant [3] and vasopressor [7]. There were few case reports which highlighted the effectiveness of DAPT in the treatment of capsular warning syndrome. The combination of aspirin and clopidogrel (DAPT) is believed to inhibit platelet aggregation via the P2Y12-receptor, prostaglandin, and thromboxane A2 pathways. One case series reported in two CWS patients who had no symptoms of progression following DAPT [17] and another retrospective study showed that DAPT was associated with improved functional outcomes in the early neurolog- 
ical deficit and decreased clinical fluctuations [18]. Meanwhile, Hawkes et al. found that intravenous thrombolysis and DAPT were both effective in reducing fluctuating symptoms in a large group of patients with capsular or stuttering lacunar syndrome (SLS) [19]. On the other hand, Kawano et al. addressing the loading dose of clopidogrel combined with other antithrombotic therapy may be an effective treatment for CWS [20]. Single antiplatelet, intravenous heparin and combination aspirin and dipyridamole were less effective in CWS [19]. In our case, we used DAPT to treat CWS and the functional outcome was slightly favourable. There was no further neurological deterioration in the patient following the 90-day post-treatment outcome assessment. Pressure therapy (mainly phenylephrine) has also been suggested for the treatment of choice. The assumption of its benefit is based on the penetrating vessel hypoperfusion related to blood pressure fluctuations. To date, our patient did not experience a decrease in blood pressure (hypoperfusion) during neurological fluctuations episodes. In summary, we report a case of CWS with fluctuating neurological symptoms showing consistent and favourable outcomes at 90 days of treatment with DAPT. In the light of this single case report, we would suggest a randomized control study to clarify the role of DAPT as one of the important therapeutic options for CWS patients.

\section{Funding}

This research received no specific grant from any funding agency in the public, commercial, or not-for-profit sectors.

\section{Informed Consent}

Written informed consent was obtained from the patient in order to publish this case report.

\section{Authorship Contributions}

Idea/Concept: Azliza İbrahim, Ahmad Firdaus; Control/Supervision: Alvin Oliver Payus.

Data Collection and/or Processing: Azliza Ibrahim, Ahmad Firdaus.

Literature Review: Azliza Ibrahim, Alvin Oliver Payus.

Writing the Article: Azliza İbrahim.

\section{Conflicts of Interest}

No conflicts of interest between the authors and/or family members of the scientific and medical committee members or members of the potential conflicts of interest, counselling, expertise, working conditions, shareholding, and similar situations in any firm.

\section{References}

[1] Tassi, R., et al. (2013) Stroke Warning Syndrome: 18 New Cases. Journal of the 
Neurological Sciences, 331, 168-171. https://doi.org/10.1016/j.jns.2013.05.027

[2] Paul, N.L.M., et al. (2012) Population-Based Study of Capsular Warning Syndrome and Prognosis after Early Recurrent TIA. Neurology, 79, 1356.

https://doi.org/10.1212/WNL.0b013e31826c1af8

[3] Donnan, G.A., et al. (1993) The Capsular Warning Syndrome. Neurology, 43, 957-962. https://doi.org/10.1212/WNL.43.5.957

[4] Garcia-Esperon, C., et al. (2016) Fluctuating Locked-In Syndrome as a Presentation of a Bilateral Pontine Infarction. The Neuroradiology Journal, 29, 347-349. https://doi.org/10.1177/1971400916658896

[5] Camps-Renom, P., et al. (2015) Clinical Characteristics and Outcome of the Capsular Warning Syndrome: A Multicenter Study. International Journal of Stroke, 10, 571-575. https://doi.org/10.1111/ijs.12432

[6] Lalive, P.H., Mayor, I. and Sztajzel, R. (2003) The Role of Blood Pressure in Lacunar Strokes Preceded by TIAs. Cerebrovascular Diseases, 16, 88-90.

https://doi.org/10.1159/000070121

[7] Mistri, A.K., Robinson, T.G. and Potter, J.F. (2006) Pressor Therapy in Acute Ischemic Stroke: Systematic Review. Stroke, 37, 1565-1571. https://doi.org/10.1161/01.STR.0000222002.57530.05

[8] Fahey, C.D., Alberts, M.J. and Bernstein, R.A. (2005) Oral Clopidogrel Load in Aspirin-Resistant Capsular Warning Syndrome. Neurocritical Care, 2, 183-184. https://doi.org/10.1385/NCC:2:2:183

[9] Teng, H.W. and Hong, C.T. (2008) Capsular Warning Syndrome: Report of a Case. Acta Neurologica Taiwanica, 17, 248-252.

[10] Vivanco-Hidalgo, R.M., et al. (2008) Thrombolysis in Capsular Warning Syndrome. Cerebrovascular Diseases, 25, 508-510. https://doi.org/10.1159/000131109

[11] Gutiérrez Ruano, B., et al. (2013) Intravenous Thrombolysis in Capsular Warning Syndrome: Is It Beneficial? Neurología (English Edition), 28, 444-446. https://doi.org/10.1016/j.nrleng.2012.03.022

[12] He, L., et al. (2019) Capsular Warning Syndrome: Clinical Analysis and Treatment. BMC Neurology, 19, 285. https://doi.org/10.1186/s12883-019-1522-0

[13] Donnan, G.A., Tress, B.M. and Bladin, P.F. (1982) A Prospective Study of Lacunar Infarction Using Computerized Tomography. Neurology, 32, 49.

https://doi.org/10.1212/WNL.32.1.49

[14] Ladeira, F., et al. (2017) Capsular Warning Syndrome: The Role of Blood Pressure. Journal of the Neurological Sciences, 381, 20-21. https://doi.org/10.1016/j.jns.2017.08.008

[15] Terai, S., et al. (2000) Mechanism in Progressive Lacunar Infarction: A Case Report with Magnetic Resonance Imaging. Archives of Neurology, 57, 255-258. https://doi.org/10.1001/archneur.57.2.255

[16] Saposnik, G., Noel de Tilly, L. and Caplan, L.R. (2008) Pontine Warning Syndrome. Archives of Neurology, 65, 1375-1377. https://doi.org/10.1001/archneur.65.10.1375

[17] Asil, T., et al. (2012) Combined Antithrombotic Treatment with Aspirin and Clopidogrel for Patients with Capsular Warning Syndrome: A Case Report. Neurologist, 18, 68-69. https://doi.org/10.1097/NRL.0b013e318247b9a5

[18] Berberich, A., et al. (2019) Dual Antiplatelet Therapy Improves Functional Outcome in Patients with Progressive Lacunar Strokes. Stroke, 50, 1007-1009. https://doi.org/10.1161/STROKEAHA.118.023789

[19] Hawkes, M.A., et al. (2019) Can We Stop the Stuttering in Stroke? Interventions in 
40 Patients with Acute Lacunes. Journal of the Neurological Sciences, 401, 1-4. https://doi.org/10.1016/j.jns.2019.04.009

[20] Kawano, H., et al. (2014) Loading Dose of Clopidogrel in Combination with Other Antithrombotic Therapy for Capsular Warning Syndrome. Journal of Stroke \& Cerebrovascular Diseases, 23, 1265-1266.

https://doi.org/10.1016/j.jstrokecerebrovasdis.2013.09.020 